\title{
Protective effects of monoclonal antibodies against lethal canine distemper virus infection in mice
}

\author{
Norio Hirayama, ${ }^{1 *}$ Megumi Senda, ${ }^{1}$ Naohiko Nakashima, ${ }^{1}$ Masami Takagi, ${ }^{1}$ Makoto Sugiyama, ${ }^{2}$ \\ Yasuhiro Yoshikawa ${ }^{3}$ and Kazuya Yamanouchi ${ }^{4}$
}

\begin{abstract}
${ }^{1}$ National Veterinary Assay Laboratory, Ministry of Agriculture, Forestry and Fisheries, 1-15-1 Tokura, Kokubunji, Tokyo 185, 2 Department of Veterinary Public Health, Faculty of Agriculture, Gifu University, Yanagido, Gifu 501-11, ${ }^{3}$ Tsukuba Primate Center, National Institute of Health, Tsukuba, Ibaraki 305 and ${ }^{4}$ Laboratory Animal Research Center, Institute of Medical Science, University of Tokyo, Minato-ku, Tokyo 108, Japan
\end{abstract}

Monoclonal antibodies (MAbs) against the haemagglutinin $(\mathrm{H})$, fusion protein $(\mathrm{F})$ and nucleoprotein of canine distemper virus (CDV) were examined for their ability to protect mice against lethal $\mathrm{CDV}$ infection. One MAb against $\mathrm{H}$ and two of six MAbs against $F$ protected mice, the protective effect of the anti-H MAb being stronger than that of the anti-F MAbs. The anti$H$ MAb showed virus neutralizing activity, but the two anti-F MAbs, which recognized the same epitope, did not. Protection by the anti-F MAbs correlated with cell fusion inhibition, but not with complement-dependent neutralization, complement-dependent cytolysis or antibody-dependent cell-mediated cytotoxicity. These results suggest that neutralization by antibody against $\mathrm{H}$ and cell fusion inhibition by antibody against $\mathrm{F}$ play important roles in the protective mechanism against CDV infection.
Canine distemper virus (CDV) is a member of the genus morbillivirus in the family Paramyxoviridae (Kingsbury et al., 1978). The virus envelope consists of two glycoproteins, haemagglutinin $(\mathrm{H})$ and the fusion protein (F), which have an important role in infection and the subsequent expression of pathogenicity. In general, antibodies against $\mathrm{H}$ or haemagglutinin-neuraminidase of paramyxoviruses have neutralizing activity and inhibit virus attachment, and antibodies against $F$ prevent the spread of infection. The protective effects of anti-F antibodies are particularly important in some paramyxoviruses (Löve et al., 1986; Meulemans et al., 1986; Örvell \& Grandien, 1982; Rydbeck et al., 1988). In dogs, immunity to $F$ restricts the spread of CDV infection more efficiently than immunity to $\mathrm{H}$ (Norrby $e t$ al., 1986). In this study, we examined monoclonal antibodies (MAbs) against these two glycoproteins for their ability to protect BALB/c mice against lethal CDV challenge to evaluate the role of each antibody.

The FXNO strain of CDV (Hirayama et al., 1985) was used unless otherwise indicated. In some experiments the YSA-TC strain of CDV (Hirayama et al., 1986), the LA strain of rinderpest virus (RPV) and the Edmonston strain of measles virus (MV) (Sugiyama et al., 1989) were also used.

For the production of MAbs, BALB/c mice were injected intraperitoneally (i.p.) with $10^{8}$ p.f.u. of virus and boosted four or five times at 3 week intervals with the same antigen. Their spleens were removed 3 days after the last injection and fused with P3-X63-Ag8-U1 myeloma cells by adding polyethylene glycol 4000 (Merck). Culture supernatants from the hybridoma cells were screened for antibody production by the indirect immunoperoxidase technique (Minamoto et al., 1981) using virus-infected Vero cells as the antigen. Hybridoma cell clones were expanded and injected into the peritoneal cavity of pristane-treated $B A L B / c$ mice, and the ascites collected and used as the source of MAbs.

For the virus neutralization test, murine neuroblastoma (MN) cells in 96-well microplates were used. In some experiments, fresh BALB/c mouse serum $(1: 5)$ was added to the virus-serum mixture as a source of complement.

Complement-dependent cytolysis (CDC) and antibody-dependent cell-mediated cytotoxicity (ADCC) tests were carried out as described by Rector et al. (1982), virus-infected $\mathrm{MN}$ cells being used as the target. In the $\mathrm{ADCC}$ test, the effector cells were the peritoneal exudate of BALB/c mice induced by proteose peptone; an effector : target cell ratio of $10: 1$ was used. In both tests, the extent of cytolysis or cytotoxicity was determined by the 3-(4,5-dimethylthiazol-2-yl)-2,5-diphenyltetrazolium bromide (MTT; Sigma) assay (Mosmann, 1983). Briefly $0.5 \%$ MTT was used and formazan was extracted with 
Table 1. Immunoreactivity of anti-CDV MAbs with various strains of morbillivirus

\begin{tabular}{|c|c|c|c|c|c|c|}
\hline \multirow[b]{3}{*}{ MAb } & \multirow[b]{3}{*}{ Isotype } & \multirow{3}{*}{$\begin{array}{l}\text { Antigenic } \\
\text { site }\end{array}$} & \multicolumn{4}{|c|}{ IFA titre $\left(\log _{10}\right)$ against } \\
\hline & & & \multicolumn{2}{|c|}{$\mathrm{CDV}$} & \multirow[b]{2}{*}{ RPV } & \multirow[b]{2}{*}{ MV } \\
\hline & & & FXNO & YSA-TC & & \\
\hline$d-7$ & $\operatorname{IgG} 2 a$ & $\mathrm{H}$ & 6 & 5 & $<2$ & $<2$ \\
\hline$k-1$ & $\operatorname{IgG} 2 \mathrm{a}$ & FI & 5 & 5 & 4 & 4 \\
\hline g-1 & IgG2a & FI & 6 & 5 & 4 & 4 \\
\hline $\mathrm{f}-7$ & $\operatorname{IgG} 2 \mathrm{a}$ & FII & 6 & 5 & 4 & 5 \\
\hline$b-8$ & IgG2a & FII & 6 & 5 & 4 & 4 \\
\hline$a-3$ & $\operatorname{IgG} 2 \mathrm{a}$ & FIII & 6 & 4 & 3 & 3 \\
\hline$a-8$ & IgG2a & FIV & 5 & 2 & $<2$ & $<2$ \\
\hline$f-5$ & $\operatorname{IgG} 2 \mathrm{a}$ & NPI & 6 & 5 & 3 & $<2$ \\
\hline$e-6$ & IgG2b & NPII & 6 & 6 & $<2$ & $<2$ \\
\hline$c-5$ & $\operatorname{IgG} 2 \mathrm{a}$ & NPIII & 5 & $<2$ & $<2$ & $<2$ \\
\hline
\end{tabular}

dimethyl sulphoxide (Takamatsu \& Murata, 1986). The highest dilution of MAb that produced $20 \%$ cytolysis or cytotoxicity was taken as the antibody titre in the CDC or ADCC tests.

A cell fusion inhibition (FI) test was carried out on MN cells infected with virus at a multiplicity of $0 \cdot 1$. After adsorption for $1.5 \mathrm{~h}$ at $37^{\circ} \mathrm{C}$, cells were treated with glycine-hydrochloride-buffered saline $\mathrm{pH} 3.0$ for 5 min on ice to inactivate virus which had not penetrated the cell (Hirayama et al., 1985). The dispersed cells were resuspended in a small volume of PBS and Vero cells grown in $6 \mathrm{~cm}$ plastic dishes were inoculated with $0.1 \mathrm{ml}$ of the infected $\mathrm{MN}$ cell suspension. After adsorption, dishes were overlaid with agar medium (Hirayama et al., 1978) containing $\mathrm{MAb}$ and the number of plaques was counted 6 days later. The highest dilution of an MAb producing $50 \%$ plaque formation inhibition was taken as the FI titre.

A total of 54 hybridoma cell lines were established from several independent fusions. Viral polypeptide specificity was determined by immunoprecipitation (Hirayama et al., 1985) and Western blotting (Bunschoten et al., 1989). Of the $54 \mathrm{MAbs}$, one recognized $\mathrm{H}, 29 \mathrm{~F}_{1}$ and four the nucleoprotein (NP); the specificity of the remaining 20 MAbs could not be determined.

Ten MAbs were examined for their antigenic specificity by an indirect fluorescent antibody (IFA) test (Table 1). Antigenic sites on F and NP were identified by their reactivity with MAbs against morbillivirus strains, and a competitive binding assay (data not shown). Four antigenic sites (FI to FIV) were distinguished using antiF MAbs, three (NPI to NPIII) using anti-NP MAbs.

Using these 10 MAbs we attempted to protect mice against lethal CDV infection. Each group of 10 4- to 5day-old BALB/c mice was injected i.p. with $0 \cdot 1 \mathrm{ml}$ of MAb. Immediately thereafter, mice were challenged

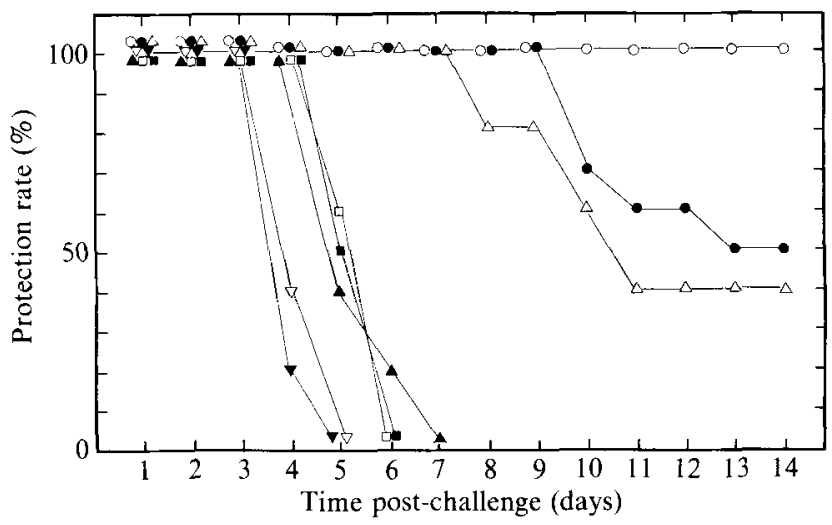

Fig. 1. Protective effect of MAbs against lethal CDV infection in suckling mice. Groups of 10 mice were given $0.1 \mathrm{ml}$ of $\mathrm{MAb}$ and challenged i.c. with $100 \mathrm{LD}_{50}$ of $\mathrm{CDV}$. Clinical signs were monitored for 14 days. MAbs were d-7 (O), k-1 (O), g-1 $\triangle$ ), f-7 ( $)$, b-8 ( $\square)$, a-3 $(\square)$, e-6 $(\nabla)$, and a-8, f-5, c-5 and control $(\nabla)$.

intracerebrally (i.c.) with $100 \mathrm{LD}_{50}$ of virus. As shown in Fig. 1, anti-H MAb d-7 prevented mice developing clinical signs, whereas anti-F MAbs k-1 and g-l were partially protective, some mice developing clinical signs 8 days post-challenge; no protective effect was observed with the other anti-F (f-7, b-8, a-3 and a-8) and anti-NP ( $f-5$, e-6 and $c-5$ ) MAbs. Clinical signs such as wandering, jumping and circling appeared 4 or 5 days postchallenge, a marked decrease in body weight and paralysis were observed, and all mice died between 5 and 7 days after the appearance of symptoms. Pathological lesions were localized in the central nervous system, with a pattern similar to that described by Sawada (1967).

The protective effects of these MAbs were confirmed by the recovery of virus from the brains of challenged mice. Virus was detected from 2 days post-challenge $\left(10^{2 \cdot 8} \mathrm{TCID}_{50} / 0 \cdot 25 \mathrm{~g}\right)$, and high titres $\left(10^{4 \cdot 5} \mathrm{TCID}_{50} / 0.25\right.$ g) were present until death in the brains of mice which received non-effective MAbs or control ascitic fluid. No virus was detectable in those mice which were clinically protected by MAbs.

The $50 \%$ effective dose $\left(\mathrm{ED}_{50}\right)$ of an anti-H (d-7) and an anti-F (k-1) MAb was the reciprocal of the MAb dilution that protected $50 \%$ of mice against challenge with $100 \mathrm{LD}_{50}$ virus; the protection index was the decrease $\left(\log _{10}\right)$ in $L D_{50}$ produced by the administration of an MAb. At the same Ig concentration, the $\mathrm{ED}_{50}$ of the anti-H and anti-F MAbs was 11.3 and 1.1 respectively; the protection indices were 4.0 and 2.7 respectively. To determine whether passive transfer of MAbs could alter the course of an established infection, MAbs were given to mice 1 to 4 days after i.c. challenge with virus; anti-H MAb was effective up to 3 days postchallenge, and anti-F MAb at 1 day. These results 
Table 2. Immunological activity of MAbs in vitro

\begin{tabular}{|c|c|c|c|c|c|c|c|}
\hline \multirow[b]{3}{*}{ MAb } & \multirow{3}{*}{$\begin{array}{l}\text { Antigenic } \\
\text { site }\end{array}$} & \multicolumn{2}{|c|}{ Neutralization titre } & \multirow{2}{*}{\multicolumn{3}{|c|}{ Titre }} & \multirow{3}{*}{$\begin{array}{c}\text { Protection } \\
\text { rate }(\%)\end{array}$} \\
\hline & & \multirow{2}{*}{$\begin{array}{l}\text { Without } \\
\text { complement }\end{array}$} & \multirow{2}{*}{$\begin{array}{c}\text { With } \\
\text { complement }\end{array}$} & & & & \\
\hline & & & & $\mathrm{CDC}$ & $\mathrm{ADCC}$ & FI & \\
\hline$d-7$ & $\mathbf{H}$ & 1280 & 10240 & $\mathrm{NT}^{*}$ & NT & NT & 100 \\
\hline$k-1$ & FI & $<10$ & 160 & 20480 & 5120 & 100 & 50 \\
\hline$g-1$ & FI & $<10$ & 320 & 5120 & 2560 & 50 & 40 \\
\hline $\mathrm{f}-7$ & FII & $<10$ & 320 & 5120 & 5120 & $<25$ & 0 \\
\hline$b-8$ & FII & $<10$ & 320 & 10240 & 2560 & $<25$ & 0 \\
\hline$a-3$ & FIII & $<10$ & 320 & 10240 & 2560 & $<25$ & 0 \\
\hline$a-8$ & FIV & $<10$ & $<10$ & 20 & $<20$ & $<25$ & 0 \\
\hline$f-5$ & NPI & $<10$ & $<10$ & NT & NT & NT & 0 \\
\hline$e-6$ & NPII & $<10$ & $<10$ & NT & NT & NT & 0 \\
\hline$c-5$ & NPIII & $<10$ & $<10$ & $<20$ & $<20$ & $<25$ & 0 \\
\hline
\end{tabular}

* NT, Not tested.

indicated that the protective efficacy of the anti-H MAb was higher than that of the anti-F MAb.

To determine the mechanism of protection, the immunological activity of MAbs in vitro was examined (Table 2). Only anti-H MAb d-7 was found to have neutralizing activity, but five of the six anti-F MAbs had neutralizing activity in the presence of mouse complement. Complement-dependent neutralizing activity titres of MAbs were almost the same regardless of whether they were protective in vivo.

CDC, ADCC and FI tests were carried out to determine the mechanism of protection by anti-F MAbs. As shown in Table 2, all anti-F MAbs except MAb a-8 had high $\mathrm{CDC}$ and $\mathrm{ADCC}$ activities. Plaque formation was inhibited under overlay medium containing MAbs k-1 or g-1. FI titres of MAbs k-1 and g-1 were 100 and 50, respectively, and those of the other anti-F MAbs were less than 25, indicating that the FI activity of the anti-F MAbs correlated with protection in vivo.

The present study has shown that MAbs against $\mathrm{H}$ and $F$ of CDV protect mice against lethal CDV challenge. The protective effect of the anti-H MAb was stronger than that of anti-F MAbs, which do not have neutralizing activity. This result is compatible with a previous report that showed a correlation between the titre of a neutralizing antibody and protection in dogs (Gillespie et al., 1958). Since only one anti-H MAb was available, the protective effect of anti-H MAbs recognizing the other epitopes remains to be determined.

This study has revealed that one epitope of $F$ participates in the protective effect. Two anti-F MAbs recognizing the same epitope protect mice, indicating that this epitope plays an important role in CDV infection.

In previous studies, neutralizing and non-neutralizing activities of anti- $\mathrm{F}$ antibodies have been identified. For example, the protective effect of MAbs against the F of Newcastle disease virus (Meulemans et al., 1986), Sendai virus (Örvell \& Grandien, 1982) and parainfluenza virus type 3 (Rydbeck et al., 1988) has been shown to be produced by neutralizing activity whereas the protective activity of non-neutralizing MAbs against the $F$ of mumps virus was considered to be relevant to CDC or ADCC (Löve et al., 1986). In the present study, only MAbs which protected mice had FI activity, whereas complement-dependent neutralizing activity, ADCC and CDC were found for all MAbs regardless of protective capacity. These results suggest that the inhibition of cell-to-cell spread of virus in the brain may be responsible for the protective effect of anti-F MAbs.

\section{References}

Bunschoten, H., Gore, M., Claassen, I. J. Th. M., UytdehaAg, F. G. C. M., Dietzschold, B., Wunner, W. H. \& Osterhaus, A. D. M. E. (1989). Characterization of a new virus-neutralizing epitope that denotes a sequential determinant on the rabies virus glycoprotein. Journal of General Virology 70, 291-298.

Gillespie, J. H., BaKer, J. A., Burgher, J., Robson, D. \& Gilman, B. (1958). The immune response of dogs to distemper virus. Cornell Veterinarian 48, 103-126.

Hirayama, N., Minamoto, N. \& Kurata, K. (1978). Plaque formation by canine distemper virus in Vero cells. Annual Report of the National Veterinary Assay Laboratory 15, 37-42.

Hirayama, N., Senda, M., Kurata, K., Yoshikawa, Y. \& YAMANOUCHI, K. (1985). Requirement of methionine for the replication of canine distemper virus in Vero cells. Journal of General Virology 66, 149-157.

Hirayama, N., Senda, M., Yamamoto, H., Kurata, K., Yoshikawa, Y. \& Yamanouchi, K. (1986). Comparison of biological and molecular properties among canine distemper virus strains. Japanese Journal of Veterinary Science 48, 259-265.

Kingsbury, D. W., Bratt, M. A., Choppin, P. W., hanson, R. P., Hosaka, Y., ter Meulen, V., Norrby, E., Plowright, W., Rott, R. \& WUNNER, W. H. (1978). Paramyxoviridae. Intervirology 10, $137-152$. 
Löve, A., Rydbeck, R., Utter, G., Örvell, C., Kristensson, K. \& NoRrBY, E. (1986). Monoclonal antibodies against the fusion protein are protective in necrotizing mumps meningoencephalitis. Journal of Virology 58, 220-222.

Meulemans, G., Gonze, M., Carlier, M. C., Petit, P., Burny, A. \& LONG, L. (1986). Protective effects of HN and F glycoproteinspecific monoclonal antibodies on experimental Newcastle disease. Avian Pathology 15, 761-768.

Minamoto, N., Hirayama, N., Kurata, K., Sazawa, H. \& Kinjo, T. (1981). A microassay for the quantitation of rabies virus by an immunoperoxidase technique. Research Bulletin of the Faculty of Agriculture, Gifu University 45, 187-196.

MosmanN, T. (1983). Rapid colorimetric assay for cellular growth and survival: application to proliferation and cytotoxicity assays. Journal of Immunological Methods 65, 55-63.

Norrby, E., Utter, G., Örvell, C. \& APPel, M. J. G. (1986). Protection against canine distemper virus in dogs after immunization with isolated fusion protein. Journal of Virology 58, 536541 .

ÖrvelL, C. \& Grandien, M. (1982). The effects of monoclonal antibodies on biologic activities of structural proteins of Sendai virus. Journal of Immunology 129, 2779-2787.
Rector, J. T., LAUSCH, R. N. \& OAKES, J. E. (1982). Use of monoclonal antibodies for analysis of antibody-dependent immunity to ocular herpes simplex virus type 1 infection. Infection and Immunity 38, $168-174$.

RYDbecK, R., Löve, A. \& NorRby, E. (1988). Protective effects of monoclonal antibodies against parainfluenza virus type 3-induced brain infection in hamsters. Journal of General Virology 69, $1019-1024$.

SAWADA, M. (1967). Pathological studies on canine distemper. Histopathological changes in mice infected with experimental canine distemper. Annual Report of the National Veterinary Assay Laboratory 5, 122 -130.

Sugiyama, M., Minamoto, N., Kinjo, T., Hirayama, N., Sasaki, H., Yoshixawa, Y. \& Yamanouchi, K. (1989). Characterization of monoclonal antibodies against four structural proteins of rinderpest virus. Journal of General Virology 70, 2605-2613.

Takamatsu, H. \& Murata, H. (1986). MTT-DMSO assay: an improved colorimetric assay for the evaluation of cellular and immune function. Bulletin of the National Institute of Animal Health 89, 27-37.

(Received 12 March 1991; Accepted 15 July 1991) 